\title{
Towards Full Utilization of Biomass Resources: A Case Study on Industrial Hemp Residue and Spent Mushroom Substrate
}

\author{
Wubliker Dessie ${ }^{1,2} \mathbb{D}$, Xiaofang Luo ${ }^{1,2}$, Jiachen Tang ${ }^{1}$, Wufei Tang ${ }^{1}$, Meifeng Wang ${ }^{1}$, Zuodong Qin ${ }^{1,2, *}$ \\ and Yimin Tan $2, *$ \\ 1 Hunan Engineering Technology Research Center for Comprehensive Development and Utilization of \\ Biomass Resources, Yongzhou 425199, China; dwubliker@yahoo.com (W.D.); \\ kong870122wxfx@163.com (X.L.); Tangjc0317@163.com (J.T.); buctfiresafetytwf@163.com (W.T.); \\ wmf0713@163.com (M.W.) \\ 2 China College of Packaging and Materials Engineering, Hunan University of Technology, \\ Zhuzhou 412007, China \\ * Correspondence: qinzd@njtech.edu.cn (Z.Q.); yimin.tan@hut.edu.cn (Y.T.)
}

Citation: Dessie, W.; Luo, X.; Tang, J.; Tang, W.; Wang, M.; Qin, Z.; Tan, Y. Towards Full Utilization of Biomass Resources: A Case Study on Industrial Hemp Residue and Spent Mushroom Substrate. Processes 2021, 9, 1200. https://doi.org/10.3390/ pr9071200

Academic Editor: Alberto J. Moya

Received: 11 June 2021

Accepted: 6 July 2021

Published: 12 July 2021

Publisher's Note: MDPI stays neutral with regard to jurisdictional claims in published maps and institutional affiliations.

Copyright: (c) 2021 by the authors. Licensee MDPI, Basel, Switzerland. This article is an open access article distributed under the terms and conditions of the Creative Commons Attribution (CC BY) license (https:/ / creativecommons.org/licenses/by/ $4.0 /)$.

\begin{abstract}
This was early-stage, proof-of-concept research on the full utilization of biomass resources. The current study considered industrial hemp residue (IHR) and spent mushroom substrate (SMS) to demonstrate the initial upstream steps towards the total valorization of biomass. Accordingly, different pretreatment methods such as autohydrolysis, thermal hydrolysis, and thermochemical hydrolysis methods were employed against individual and various mix ratios of IHR and SMS. To this end, raw materials, hydrolysates, and residual solids were analyzed to gain some insights, identify gaps, and suggest future research directions in this area. Implementation of the full utilization of biomass resources is, in fact, not only a matter of transforming the resources into valuable products, but it is also a plausible waste management strategy in the quest towards the development of a circular bioeconomy and sustainable future.
\end{abstract}

Keywords: spent mushroom substrate; industrial hemp; pretreatment; lignocellulose; full biomass utilization; oxalic acid

\section{Introduction}

Continuous growth in the human population obviously leads to high demand and consumption of resources. Unfortunately, the majority of these demands rely on fossil-based sources. One previous report, for example, indicated that nearly $85 \%$ of the total global energy is generated from fossil fuels [1]. On the other hand, environmental and sustainability issues associated with these resources urge us to look for ecologically friendly and renewable resources. Biomass resources are the primary candidates to fulfill such gaps [2] It is not economically or ethically feasible to use virgin resources for the synthesis of chemicals, materials, and biofuels as that could affect production of food and other primary products due to the evolving competition for land, water, and energy [3,4]. Various stages in the production and consumption of primary products certainly generate substantial amounts of waste. Improper disposal of these wastes can cause detrimental effects in terms of environmental, health, and socio-economic aspects. Encouragingly, a substantial interest has been seen in recent years to transform these waste biomass resources into value-added products. Yet, the traditional disintegrated approaches limit utilization of waste biomass mainly due to logistical issues, resources loss, inconsistent biomass quality, and other challenges $[5,6]$. Adoption of an innovative strategy for an integrated biorefinery approach that incorporates hotspot research areas such as circular economy, zero-waste, and green and sustainable chemistry could address the aforementioned underlying problems.

Waste biomass resources undergo pretreatment steps to generate fermentable feedstocks that can support microbial growth and product formation. These pretreated substrates are subjected to centrifugation and filtration to separate hydrolysates from the solid 
residues. Usually, the hydrolysates are used as the fermentation medium as they are often rich in sugars and other nutrients, while the solid residues are mostly overlooked. On the other hand, disposal of these solid residues can cause tremendous impacts. Utilization of waste biomass resources should be considered not only from an economic point of view, to transform the resources into valuable products, but also from a waste handling perspective, to avoid potential risks and apply efficient land management systems (particularly in cosmopolitan areas) [2]. Therefore, developing strategies of full/total utilization of biomass resources is crucial in this regard.

Hemp is a versatile plant with excellent agronomic and drought-resistant characteristics, and it is geographically distributed worldwide [7-9]. Its cultivation is, then, economical, and it also plays a vital role in carbon sequestration to combat global warming. Yet, exploitation of this resource for various applications generates a considerable amount of residue, which requires a proper management strategy. Similarly, mushroom cultivation and consumption have increased dramatically. For instance, in 2018, the global mushroom market reached USD 38 billion, of which China contributed more than one third (35\%), accounting for nearly half of the Asian production [10]. Specifically, production of edible mushrooms in China was estimated to be 29 million tons in 2015. Massive amounts of residues, called spent mushroom substrate (SMS) hereafter, are generated after harvesting edible mushrooms. Interestingly, this residue contains $75-85 \%$ of unused nutrients. In addition, it was reported that nearly $3.25 \mathrm{~kg}$ of SMS could be generated from every $1 \mathrm{~kg}$ of mushroom harvest [11]. Based on this estimate, 94.25 million tons of highly nutritious SMS were generated in China in 2015. On the other hand, disposal of SMS has a high financial impact in the mushroom cultivation sector. Therefore, expanding the applications of SMS would provide environmental and economic benefits.

In this study, industrial hemp residues (IHR) and SMS were considered as a proof-ofconcept for the full utilization of bioresources. Although these biomass resources have been extensively studied, the recalcitrant nature of IHR limits its potential applications. Most previously implemented hemp pretreatment strategies posed some hindrances related to efficiency, cost [7], and sustainability. Therefore, development of a feasible, green, and sustainable pretreatment strategy is vital. Different pretreatment methods such as autohydrolysis (AH), thermal hydrolysis (TH), and thermochemical hydrolysis (TCH) were employed to degrade IHR and/or SMS individually as well as with various mix ratios $(0,10$, $25,50,75,90$, and $100 \%$ ). The objectives of this early-stage research were to (1) evaluate the efficiency of various lignocellulose pretreatment methods, (2) assess the effect of blending IHR and SMS, and (3) analyze hydrolysates and solid residues so as to gain insights for implementation of the full utilization of biomass resources. To our knowledge, this is the first report to co-utilize IHR and SMS as part of an alternative pretreatment strategy, which could increase the economic value of both waste biomass resources.

\section{Experimental Section}

\subsection{Raw Materials and Chemicals}

Raw SMS and IHR (hemp hurds) were collected from Yu-xiu Hunan Biological Technology Co., Ltd., (Hunan, China) and Hunan Agricultural University (Hunan, China) (kindly provided by Prof. Zeng JIANQING), respectively. Chemicals used in this study were of analytical grade.

\subsection{Pretreatment}

IHR and SMS were smashed using a stainless-steel mini laboratory grinder and sieved to the desired particle size, $0.5 \mathrm{~mm}$, with a laboratory wire mesh sieve. In this study, a $10 \%$ mass ratio $(w / v)$ of substrates was considered. In the AH pretreatment, IHR or SMS was briefly mixed with water at room temperature. TH and TCH were completed at $121{ }^{\circ} \mathrm{C}$ for $30 \mathrm{~min}$, with the addition of $5 \%(w / v)$ oxalic acid in the latter condition, using individual and various mix ratios (0-100\%) of IHR and/or SMS. As shown in Table 1, the first (\#1-\#3) and the last (\#9-\#11) three setups were conducted to evaluate the effect of AH, 
$\mathrm{TH}$, and $\mathrm{TCH}$ pretreatment methods against individual substrates, whereas experimental

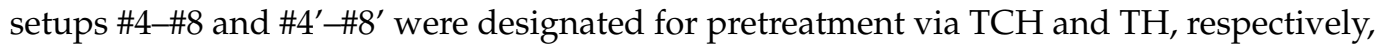
using various mix ratios of IHR and SMS. Pretreatment-wise, the current experimental

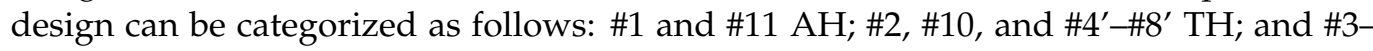
\#9 TCH. Hydrolysates were separated from the solid residues through centrifugation $(10,000 \times g, 20 \mathrm{~min})$ and filtered by Whatman no. 1 filter paper. The recovered solids were dried in the oven. These hydrolysates and solids were then used for further analyses and characterizations.

Table 1. Experimental setups and $\mathrm{pH}$ values of hydrolysates and the content of recovered solids after pretreatment of IHR and SMS.

\begin{tabular}{cccccc}
\hline SN & IHR (\%) & SMS (\%) & Pretreatment & pH & Solid Residue (\%) \\
\hline 1 & 100 & 0 & AH & $7.56 \pm 0.31$ & $88.40 \pm 1.45$ \\
2 & 100 & 0 & TH & $6.85 \pm 0.25$ & $82.80 \pm 1.08$ \\
3 & 100 & 0 & TCH & $0.48 \pm 0.01$ & $94.00 \pm 1.07$ \\
4 & 90 & 10 & TCH & $0.52 \pm 0.02$ & $97.20 \pm 1.08$ \\
$4^{\prime}$ & 90 & 10 & TH & $6.24 \pm 0.15$ & $99.10 \pm 0.51$ \\
5 & 75 & 25 & TCH & $0.51 \pm 0.01$ & $93.20 \pm 1.04$ \\
$5^{\prime}$ & 75 & 25 & TH & $6.30 \pm 0.11$ & $98.40 \pm 0.97$ \\
6 & 50 & 50 & TCH & $0.57 \pm 0.02$ & $89.80 \pm 1.62$ \\
$6^{\prime}$ & 50 & 50 & TH & $6.50 \pm 0.30$ & $87.80 \pm 0.88$ \\
7 & 25 & 75 & TCH & $0.55 \pm 0.02$ & $84.80 \pm 1.52$ \\
$7^{\prime}$ & 25 & 75 & TH & $6.70 \pm 0.23$ & $75.80 \pm 1.73$ \\
8 & 10 & 90 & TCH & $0.62 \pm 0.02$ & $82.20 \pm 1.18$ \\
$8^{\prime}$ & 10 & 90 & TH & $7.10 \pm 0.32$ & $74.00 \pm 1.63$ \\
9 & 0 & 100 & TCH & $0.65 \pm 0.02$ & $78.40 \pm 1.19$ \\
10 & 0 & 100 & TH & $6.69 \pm 0.34$ & $74.20 \pm 1.63$ \\
11 & 0 & 100 & AH & $6.86 \pm 0.33$ & $78.60 \pm 1.38$ \\
\hline
\end{tabular}

The values are means of triplicates \pm SD.

\subsection{Analytical Studies}

The reducing sugar content was analyzed using the dinitrosalicylic acid method as explained elsewhere [12].

\subsection{FTIR and SEM Analysis}

Raw materials and solid residues of the pretreated IHR and SMS were analyzed by FTIR (Fourier-transform infrared spectroscopy) and SEM (scanning electron microscope). The procedures were elucidated in our recent work [13].

\section{Results and Discussion}

\subsection{Hydrolysates and Solid Residues}

SMS is rich in lignocellulose content that could contain (\%) up to 48.7 cellulose, 34 hemicellulose, and 39.8 lignin, depending on the source of the mushroom cultivation medium [14]. Similarly, analysis of IHR content (\%) resulted in 44.5 cellulose, 32.78 hemicellulose, and 21.03 lignin [15]. In line with this, different pretreatment methods were evaluated for valorization of these bioresources. Obviously, AH and TH pretreatment methods are cost effective and avoid generation of unwanted byproducts due to the absence of chemicals. In addition, oxalic acid (OA) was employed in the TCH pretreatment. In recent years, organic acids including OA have received more attention for lignocellulosic pretreatment owing to some interesting advantages such as high efficiency and selectivity, relatively low cost, and low equipment corrosion [16,17]. More interestingly, OA can be produced from bio-based resources [18], and it can be recovered and recycled [16] in the pretreatment process, which makes the overall process greener and more sustainable.

In the $\mathrm{AH}$ pretreatment, a designated amount of crushed substrate was mixed with a proportional volume of water at room temperature. Both $\mathrm{TH}$ and $\mathrm{TCH}$ were conducted 
at $121^{\circ} \mathrm{C}$ for $30 \mathrm{~min}$, with OA being added in the latter case. The pretreatment parameters considered in this initial stage of the experiment were temperature ( $\mathrm{AH}$ vs. $\mathrm{TH})$, chemical (TH vs. TCH), and various mix ratios of substrates $(0-100 \%)$. This study generally evaluated the physical, morphological, and chemical properties of raw and pretreated substrates. Clearly, addition of OA during TCH resulted in an enormous drop in the $\mathrm{pH}$ of the hydrolysates. The hydrolysates' $\mathrm{pH}$ generally exhibited the following trend: $\mathrm{AH}>\mathrm{TH}>\mathrm{TCH}$. Keeping other factors constant, it is obvious that as the temperature rises, dissociation of water generates more $\mathrm{H}^{+}$that will lead to decreased $\mathrm{pH}$ values. Furthermore, the percentage of the recovered solid residues decreased (1) in the TH pretreatment as compared to that with the AH and TCH counterparts; and (2) as the SMS percentage increased in the mixture with IHR. TCH pretreatment of IHR and SMS mixtures apparently increased the hydrolysate volume (Figure 1) as the respective residual solid content kept decreasing (Table 1). These results explain the partial degradation of polysaccharides in the lignocellulosic biomass. Noticeably, in the case of IHR, the highest solid residues were recovered during the $\mathrm{TCH}$ process. This is probably partly due to the formation of calcium oxalate precipitates [19] via interaction of OA with calcium from the IHR. To this end, the current results demonstrated that SMS was more degradable than was IHR. The highest production of reducing sugar (data not shown) was achieved when SMS was pretreated by $\mathrm{TH}$, the next highest was achieved using the AH method. The details of the sugar production patterns are under investigation and, hence, are not thoroughly discussed in this study. Blending SMS with IHR could provide a synergistic effect. Some of the benefits of co-hydrolysis of high and low degradable biomass resources include regulation of the hydrolysis process, enhancement of the degradation efficiency and nutrient content, dilution of inhibitors, improvement of buffering actions, etc., [20,21].
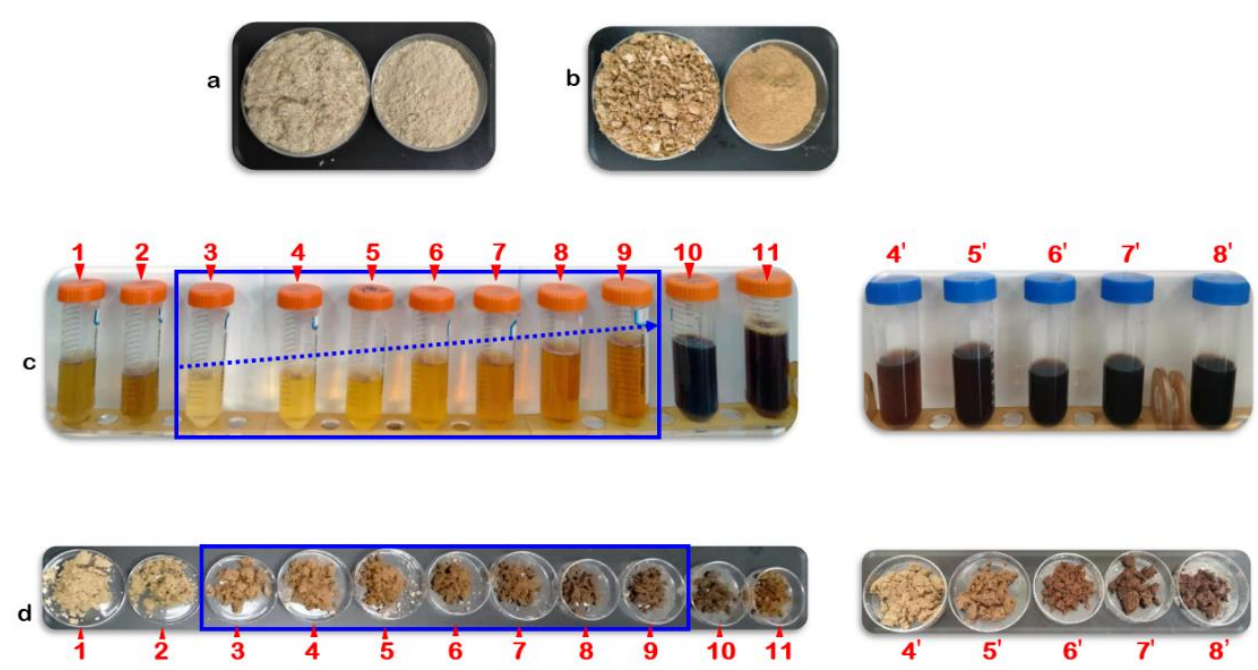

Figure 1. Photographs showing (a) SMS and (b) IHR raw materials, (c) hydrolysates, and (d) solid residues after pretreatment.

The coloration pattern of hydrolysates and solid residues unveiled variations with respect to the pretreatment method and the mix ratios of IHR and SMS. Accordingly, TH produced the darkest hydrolysates and $\mathrm{AH}$ the next darkest. Slurries in the hydrolysates of $\mathrm{AH}$ and $\mathrm{TH}$ could be undissolved fractions, potentially involved in the dark coloration of lignin [22], that would leave the hydrolysates darker and the solid residues brighter (e.g., Figure $1 \mathrm{c}, \mathrm{d} \# 1, \# 2, \# 4^{\prime}$ ). In contrast, TCH removed the colorants from the hydrolysate, making it light colored while the solid residue remained darker (e.g., Figure 1c,d; compare $\# 1, \# 2, \# 3, \# 4$, and \# 4'). In fact, previous literature has documented that OA could be used as a leaching agent to eliminate impurities from various materials [23-25]. Impressively, $\mathrm{OA}$, in the current study, possessed a dual-purpose (if not multiple purposes) for depolymerization of lignocellulose materials as well as generation of "pure" hydrolysates, making 
the process even more sustainable and economical. Furthermore, the color intensity of both hydrolysates and the solid residues became darker as the SMS percentage increased in the mixture (Figure 1c,d $\# 3-\# 9, \# 4^{\prime}-\# 8^{\prime}$ ). The dark brown coloration of SMS hydrolysates may be due to natural colorants from the initial mushroom medium substrates and/or pigmentation during mushroom cultivation stages. Such colorants are usually accompanied with toxic compounds that have antimicrobial effects [26,27]. Even though SMS contains potentially high nutrients for microbial growth and product formation, the availability of these colorants could limit its applications in this area. Therefore, efficient strategies should be developed to manage these colorants while valorizing SMS. Blending of SMS with IHR and OA pretreatment showed dilution and/or removal of colorants. Further color intensity studies will be conducted to achieve more accurate results.

\subsection{SEM Analysis}

SEM analysis was performed for four different solid samples of IHR or SMS: the raw materials (Figure $1 \mathrm{a}, \mathrm{b}$ ) and solid residues generated after $\mathrm{AH}, \mathrm{TH}$, and $\mathrm{TCH}$ pretreatments (Figure $1 \mathrm{~d}(1,2,3,9,10$, and 11)). IHR is chiefly composed of fibers. These fibers are characterized as long and intact in raw residues, shorter and partially degraded in $\mathrm{AH}$ residues, and mostly degraded in TH solid residues (Figure 2). Compactly bounded fibers began to gradually loosen sequentially and, finally, the intact grooves (Figure 2c) disappeared and smooth surfaces were observed in the TCH-treated solid residues (Figure 2d). This is possibly due to degradation of hemicellulose and alternation of lignin structures [28]. It was reported that OA plays an important role in facilitating hydrolysis process though (1) reducing the $\mathrm{pH}$ (thus, creating $\mathrm{pH}$ difference between the acidic solution and the hemp cell wall) and (2) damaging the calcium-pectate complexes of the cell walls, thereby increase susceptibility $[29,30]$.
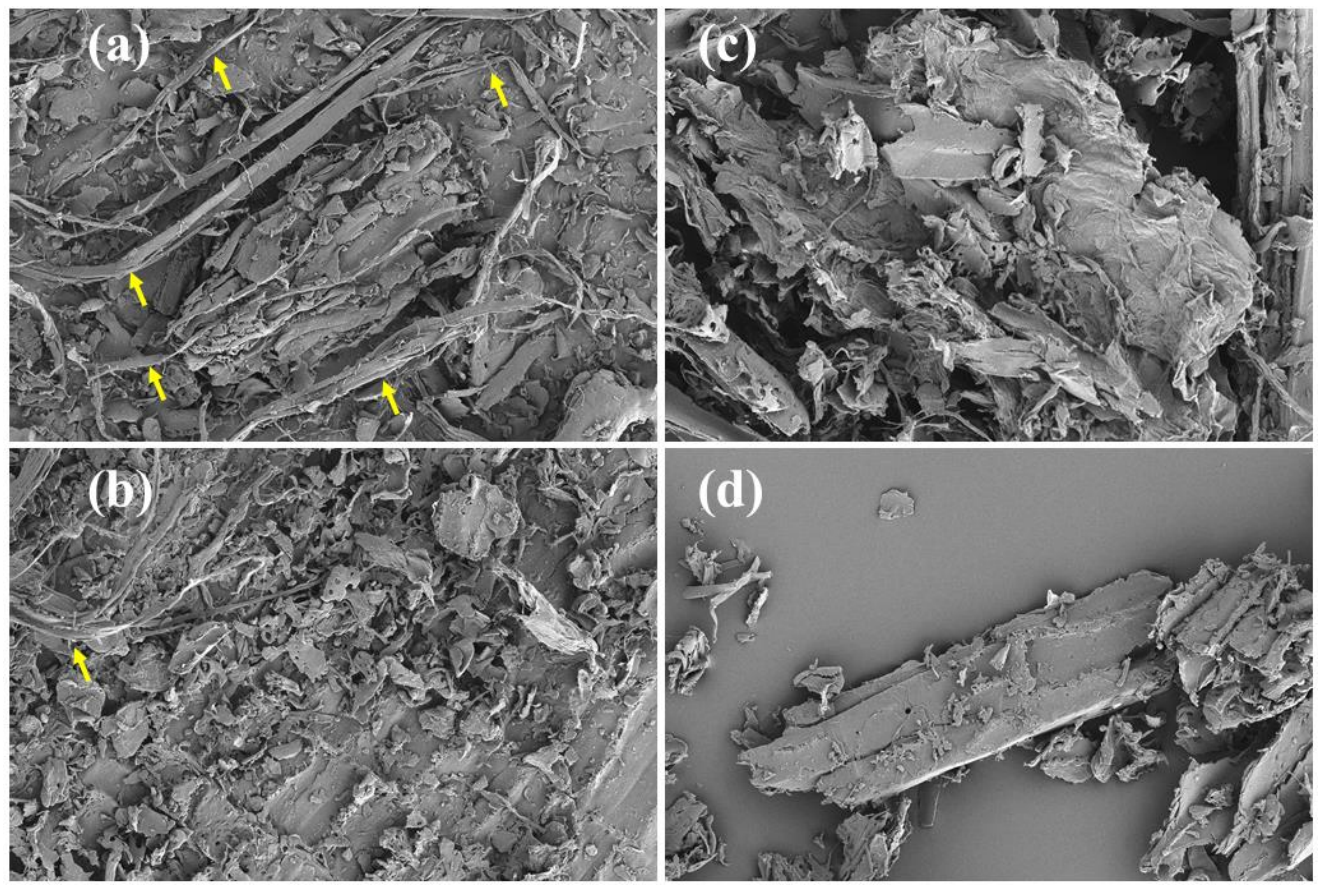

Figure 2. SEM image of (a) raw and pretreated (b) AH, (c) TH, and (d) TCH solid residues of IHR. Arrows show fibers in IHR.

Unlike IHR, secretion of the lignocellulolytic enzymes and penetration of mycelium during the previous mushroom cultivation step caused degradation of the lignocellulose components in the SMS [31]. Specifically, there were no significant structural changes between the raw and AH solid residues of SMS (Figure 3a,b). Solid residues of TH pretreated SMS started to disperse as a result of degradation of lignocellulosic biomass 
(Figure 3c). Moreover, TCH pretreatment of SMS resulted in highly fragmented solids (Figure 3d). This step probably caused the generation of products of sugars degradation. The high degradable property of SMS may not need a high concentration of acid for pretreatment. This was confirmed by the fact that AH and TH of SMS generated lower residual solid content (Table 1) and higher reducing sugar than those of TCH of SMS. It will be important to optimize conditions for acidic pretreatment of SMS to avoid loss of sugars and generation of lignocellulose pretreatment degradation products (which are inhibitory for microbial growth and fermentation).
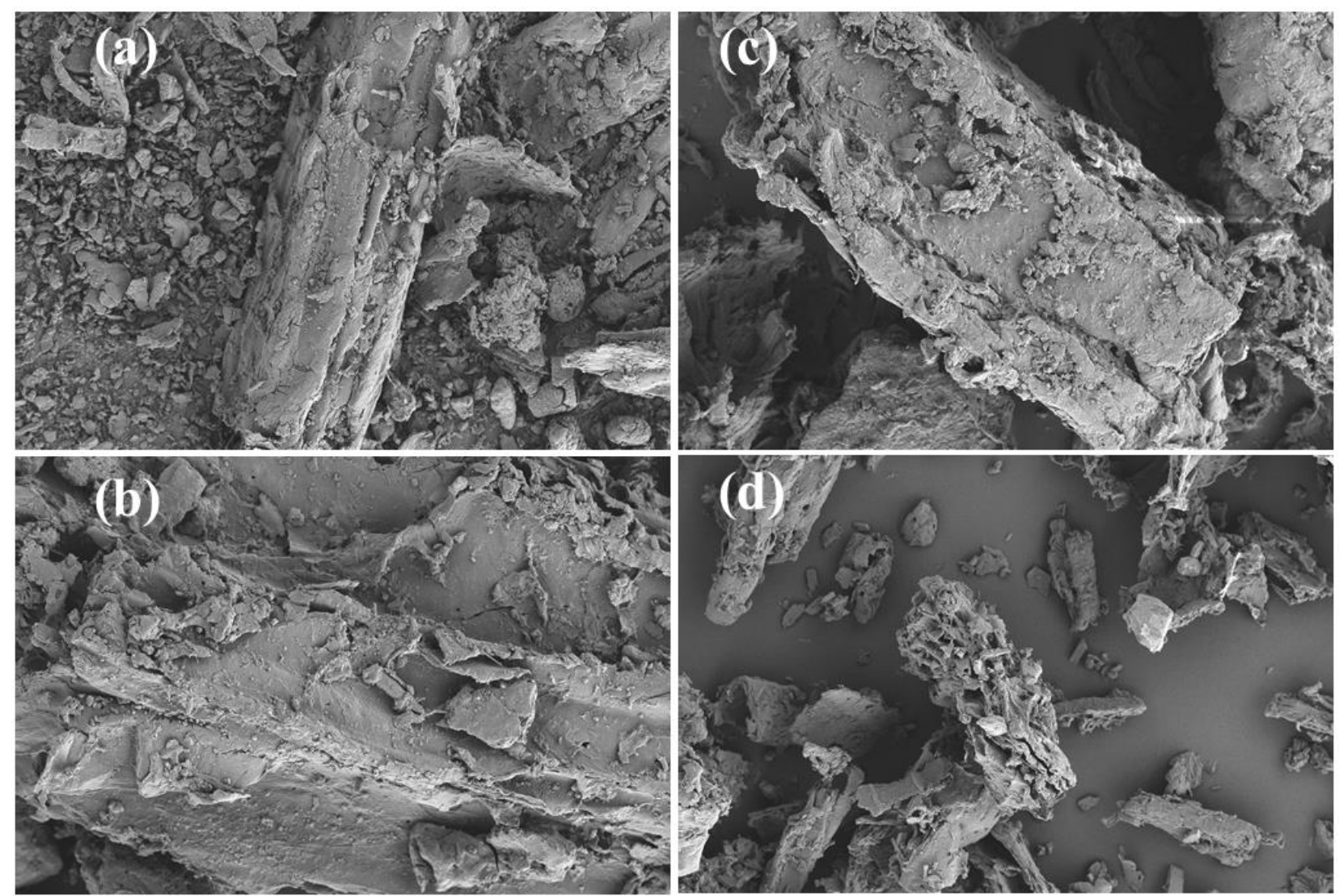

Figure 3. SEM image of (a) raw and pretreated (b) AH, (c) TH, and (d) TCH solid residues of SMS.

\subsection{FTIR Analysis}

The FTIR analysis studies were based on previously reported literature (Table 2). Similar solid samples that used for the SEM analysis were employed for the FTIR studies. Accordingly, comparison of spectrogram patterns of raw, $\mathrm{AH}, \mathrm{TH}$, and $\mathrm{TCH}$ solid residues of IHR or SMS revealed similarities, appearance/disappearance, enhancement, or formation of new peaks. Generally, raw materials and $\mathrm{AH}$ and $\mathrm{TH}$ solid residues of IHR (Figure 4) or SMS (Figure 5) exhibited similar spectra, whereas more differences were seen with respect to TCH solid residues, with a high impact on SMS. In addition, $\%$ transmittance values of IHR and SMS samples were highest (low absorption) for the raw materials and decreased (high absorption) for $\mathrm{AH}, \mathrm{TH}$, and $\mathrm{TCH}$ solid residues, in their respective order. This implies that there were high numbers of bond vibrations $(\mathrm{TCH}>\mathrm{TH}>\mathrm{AH}>\mathrm{raw})$ in the pretreated IHR and SMS. All in all, the FTIR results demonstrated the presence of obvious alternations of chemical compositions when comparing the raw material with the pretreated lignocellulosic biomass materials, with substantial changes in the OA pretreated materials. 
Table 2. Functional group assignments for raw materials and pretreated solid residues of IHR and SMS.

\begin{tabular}{|c|c|c|c|}
\hline Wavenumber $\left(\mathrm{cm}^{-1}\right)$ & Band Assignment & Remark & Ref. \\
\hline 3150-3050 & Aromatic C-H stretch & SMS-TCH & [32] \\
\hline $2250-2100$ & Alkyne $\mathrm{C} \equiv \mathrm{O}$ vibration & IHR, SMS-TCH & [32] \\
\hline 1732 & $\begin{array}{l}\text { Carbonyl } \mathrm{C}=\mathrm{O} \text { stretching } \\
\text { vibration in hemicelluloses }\end{array}$ & Enhanced in IHR-raw, AH, and TH & [28] \\
\hline 1650 & Primary amides & Enhanced in IHR-raw, $\mathrm{AH}$, and $\mathrm{TH}$ & [33] \\
\hline 1630 & $\mathrm{C}=\mathrm{C}$ stretching vibration & SMS-TCH & [34] \\
\hline 1600 & $\begin{array}{l}\mathrm{OH} \text { bending related to } \\
\text { water in hemicelluloses }\end{array}$ & IHR-raw, $\mathrm{AH}$, and $\mathrm{TH}$ & [28] \\
\hline 1512 & Aromatic skeletal vibration in lignin & All IHR, enhanced in SMS-AH, TH, and TCH & [16] \\
\hline 1430 & $\mathrm{C}-\mathrm{H}$ bending of cellulose & All IHR, enhanced in SMS-AH, TH, and TCH & [28] \\
\hline 1400 & $-\mathrm{CH}_{2}$ stretching & All IHR, enhanced in SMS-TCH & [35] \\
\hline 1368 & $\begin{array}{l}\mathrm{C}-\mathrm{OH} \text { stretching of the } \\
\text { hydrogen bond in cellulose }\end{array}$ & All IHR, enhanced in SMS-raw & [28] \\
\hline 1320 & $\mathrm{C}-\mathrm{H}_{2}$ wagging in cellulose & All IHR, enhanced in SMS-TCH & [36] \\
\hline $900-670$ & Aromatic $\mathrm{C}-\mathrm{H}$ out-of-plane bending & New peaks in SMS-TCH & [37] \\
\hline
\end{tabular}

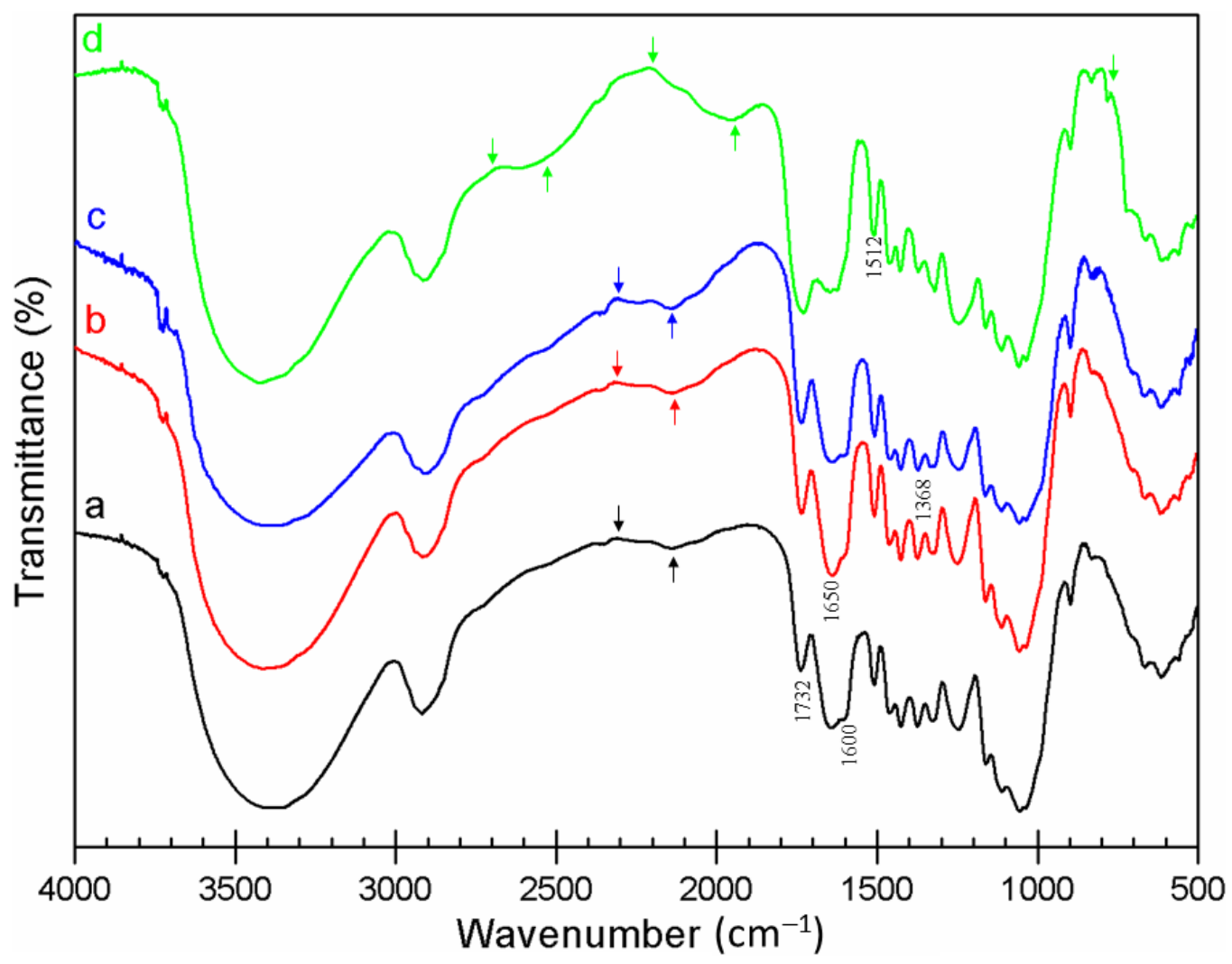

Figure 4. FTIR spectra of (a) raw and pretreated (b) AH, (c) TH, and (d) TCH solid residues of IHR. Arrows show peak variations with respect to the other samples. 


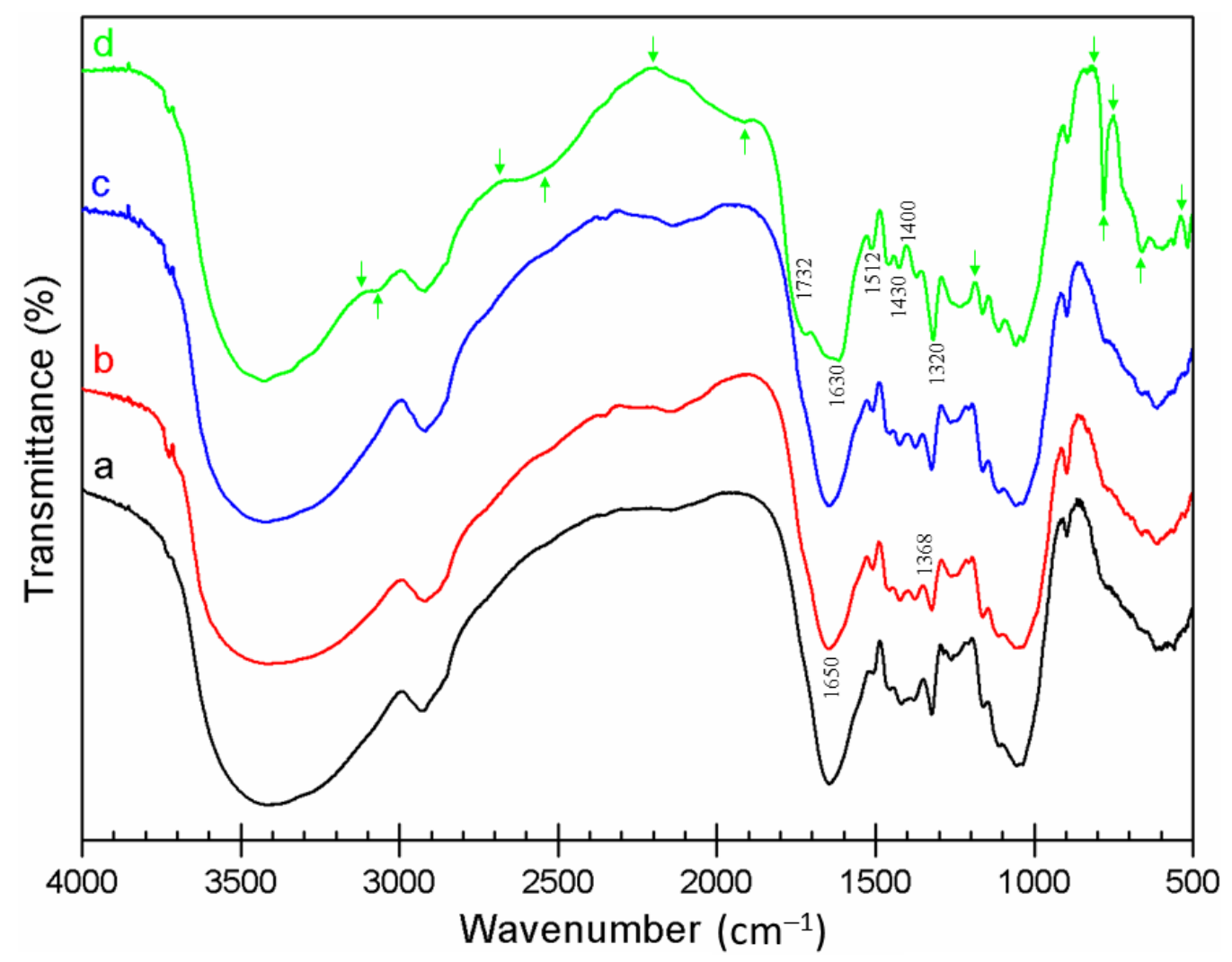

Figure 5. FTIR spectra of (a) raw and pretreated (b) AH, (c) TH, and (d) TCH solid residues of SMS. Arrows show peak variations with respect to the other samples.

\section{Conclusions}

The initial stage of this study provided insights on the degradation effects of $\mathrm{AH}, \mathrm{TH}$, and TCH on individual and mixed substrates of IHR and SMS. SMS was noticeably more degradable than was IHR, and co-hydrolysis of a mixture of these substrates provided considerable advantages. Based on these findings, future research directions were identified. Finalization of characterization and analysis studies of hydrolysates and solid residues are underway. Meanwhile, recovery of high volumes of residual solids (Table 1) after pretreatment of IHR and SMS suggested the availability of more lignocellulosic components that require further exploitation strategies. Therefore, our future research will focus on (1) optimization of the pretreatment conditions to establish the most efficient strategy, (2) transformation of hydrolysates into value-added products via microbial fermentation, and (3) implementation of potential valorization techniques for residual solids to accomplish the journey towards full and sustainable utilization of biomass resources. Pretreatment temperature, OA concentration, duration of hydrolysis, and further enzymatic saccharification conditions will be optimized accordingly.

Author Contributions: W.D. conceived and planned the experiments. The manuscript was written through contributions of all authors. All authors have read and agreed to the published version of the manuscript.

Funding: This work was supported by the Natural Science Foundation of Hunan Province (2019JJ30011) and the Furong Scholars Award Program of Hunan Province (Xiang Jiao Tong (2020) No. 58).

Institutional Review Board Statement: Not applicable.

Informed Consent Statement: Not applicable.

Data Availability Statement: Not applicable.

Conflicts of Interest: The authors declare no competing financial interest. 


\section{References}

1. Singh, D.P.; Dwevedi, A. Chapter 2-Production of clean energy by green ways. In Solutions to Environmental Problems Involving Nanotechnology and Enzyme Technology; Dwevedi, A., Ed.; Academic Press: Waltham, MA, USA, 2019; pp. 49-90. [CrossRef]

2. Dessie, W.; Luo, X.; Wang, M.; Feng, L.; Liao, Y.; Wang, Z.; Yong, Z.; Qin, Z. Current advances on waste biomass transformation into value-added products. Appl. Microbiol. Biotechnol. 2020, 104, 4757-4770. [CrossRef]

3. Godfray, H.C.J.; Beddington, J.R.; Crute, I.R.; Haddad, L.; Lawrence, D.; Muir, J.F.; Pretty, J.; Robinson, S.; Thomas, S.M.; Toulmin, C. Food Security: The Challenge of Feeding 9 Billion People. Science 2010, 327, 812-818. [CrossRef]

4. Calabrò, P.; Catalán, E.; Folino, A.; Sánchez, A.; Komilis, D. Effect of three pretreatment techniques on the chemical composition and on the methane yields of Opuntia ficus-indica (prickly pear) biomass. Waste Manag. Res. 2018, 36, 17-29. [CrossRef]

5. Nguyen, Q.A.; Smith, W.A.; Wahlen, B.D.; Wendt, L.M. Total and Sustainable Utilization of Biomass Resources: A Perspective. Front. Bioeng. Biotechnol. 2020, 8, 546. [CrossRef]

6. Fazzino, F.; Mauriello, F.; Paone, E.; Sidari, R.; Calabrò, P.S. Integral valorization of orange peel waste through optimized ensiling: Lactic acid and bioethanol production. Chemosphere 2021, 271, 129602. [CrossRef]

7. Zhao, J.; Xu, Y.; Wang, W.; Griffin, J.; Wang, D. Conversion of liquid hot water, acid and alkali pretreated industrial hemp biomasses to bioethanol. Bioresour. Technol. 2020, 309, 123383. [CrossRef] [PubMed]

8. Ingrao, C.; Lo Giudice, A.; Bacenetti, J.; Tricase, C.; Dotelli, G.; Fiala, M.; Siracusa, V.; Mbohwa, C. Energy and environmental assessment of industrial hemp for building applications: A review. Renew. Sustain. Energy Rev. 2015, 51, 29-42. [CrossRef]

9. Das, L.; Li, W.; Dodge, L.A.; Stevens, J.C.; Williams, D.W.; Hu, H.; Li, C.; Ray, A.E.; Shi, J. Comparative Evaluation of Industrial Hemp Cultivars: Agronomical Practices, Feedstock Characterization, and Potential for Biofuels and Bioproducts. ACS Sustain. Chem. Eng. 2020, 8, 6200-6210. [CrossRef]

10. Wan-Mahari, W.A.; Peng, W.; Nam, W.L.; Yang, H.; Lee, X.Y.; Lee, Y.K.; Keey, R.L.; Nyuk, L.M.; Aqilah, M.; Sonne, C.; et al. A review on valorization of oyster mushroom and waste generated in the mushroom cultivation industry. J. Hazard Mater. 2020, 400, 123156. [CrossRef] [PubMed]

11. Li, T.-H.; Che, P.-F.; Zhang, C.-R.; Zhang, B.; Ali, A.; Zang, L.-S. Recycling of spent mushroom substrate: Utilization as feed material for the larvae of the yellow mealworm Tenebrio molitor (Coleoptera: Tenebrionidae). PLoS ONE 2020, 15, e0237259. [CrossRef]

12. Miller, G.L. Use of Dinitrosalicylic Acid Reagent for Determination of Reducing Sugar. Anal. Chem. 1959, 31, 426-428. [CrossRef]

13. Luo, X.; Dessie, W.; Wang, M.; Duns, G.J.; Rong, N.; Feng, L.; Zeng, J.; Qin, Z.; Tan, Y. Comprehensive utilization of residues of Magnolia officinalis based on fiber characteristics. J. Mater. Cycles Waste Manag. 2021, 23, 548-556. [CrossRef]

14. Koutrotsios, G.; Mountzouris, K.C.; Chatzipavlidis, I.; Zervakis, G.I. Bioconversion of lignocellulosic residues by Agrocybe cylindracea and Pleurotus ostreatus mushroom fungi-Assessment of their effect on the final product and spent substrate properties. Food Chem. 2014, 161, 127-135. [CrossRef]

15. Stevulova, N.; Cigasova, J.; Estokova, A.; Terpakova, E.; Geffert, A.; Kacik, F.; Singovszka, E.; Holub, M. Properties Characterization of Chemically Modified Hemp Hurds. Materials 2014, 7, 8131-8150. [CrossRef]

16. Cheng, B.; Zhang, X.; Lin, Q.; Xin, F.; Sun, R.; Wang, X.; Ren, J. A new approach to recycle oxalic acid during lignocellulose pretreatment for xylose production. Biotechnol. Biofuels 2018, 11, 324. [CrossRef]

17. Li, C.; Huang, C.; Zhao, Y.; Zheng, C.; Su, H.; Zhang, L.; Luo, W.; Zhao, H.; Wang, S.; Huang, L.-J. Effect of Choline-Based Deep Eutectic Solvent Pretreatment on the Structure of Cellulose and Lignin in Bagasse. Processes 2021, 9, 384. [CrossRef]

18. Jiang, Z.; Zhang, Z.; Song, J.; Meng, Q.; Zhou, H.; He, Z.; Han, B. Metal-Oxide-Catalyzed Efficient Conversion of Cellulose to Oxalic Acid in Alkaline Solution under Low Oxygen Pressure. ACS Sustain. Chem. Eng. 2016, 4, 305-311. [CrossRef]

19. Vom Stein, T.; Grande, P.; Sibilla, F.; Commandeur, U.; Fischer, R.; Leitner, W.; Domínguez de María, P. Salt-assisted organic-acidcatalyzed depolymerization of cellulose. Green Chem. 2010, 12, 1844-1849. [CrossRef]

20. Lin, Y.; Ge, X.; Li, Y. Solid-state anaerobic co-digestion of spent mushroom substrate with yard trimmings and wheat straw for biogas production. Bioresour. Technol. 2014, 169, 468-474. [CrossRef] [PubMed]

21. Chakraborty, D.; Venkata-Mohan, S. Efficient resource valorization by co-digestion of food and vegetable waste using three stage integrated bioprocess. Bioresour. Technol. 2019, 284, 373-380. [CrossRef]

22. Zhang, H.; Bai, Y.; Yu, B.; Liu, X.; Chen, F. A practicable process for lignin color reduction: Fractionation of lignin using methanol/water as a solvent. Green Chem. 2017, 19, 5152-5162. [CrossRef]

23. Musiał, I.; Cibis, E.; Rymowicz, W. Designing a process of kaolin bleaching in an oxalic acid enriched medium by Aspergillus niger cultivated on biodiesel-derived waste composed of glycerol and fatty acids. Appl. Clay Sci. 2011, 52, 277-284. [CrossRef]

24. Zürner, P.; Frisch, G. Leaching and Selective Extraction of Indium and Tin from Zinc Flue Dust Using an Oxalic Acid-Based Deep Eutectic Solvent. ACS Sustain. Chem. Eng. 2019, 7, 5300-5308. [CrossRef]

25. Salmani Nuri, O.; Irannajad, M.; Mehdilo, A. Effect of surface dissolution by oxalic acid on flotation behavior of minerals. J. Mater Res. Technol. 2019, 8, 2336-2349. [CrossRef]

26. Arimi, M.M.; Zhang, Y.; Götz, G.; Kiriamiti, K.; Geißen, S.-U. Antimicrobial colorants in molasses distillery wastewater and their removal technologies. Int. Biodeterior. Biodegrad. 2014, 87, 34-43. [CrossRef]

27. Korniłłowicz-Kowalska, T.; Rybczyńska-Tkaczyk, K. Decolorization and biodegradation of melanoidin contained in beet molasses by an anamorphic strain of Bjerkandera adusta CCBAS930 and its mutants. World J. Microbiol. Biotechnol. 2020, 37, 1. [CrossRef] [PubMed] 
28. Semhaoui, I.; Maugard, T.; Zarguili, I.; Rezzoug, S.-A.; Zhao, J.-M.Q.; Toyir, J.; Nawdali, M.; Maache-Rezzoug, Z. Eco-friendly process combining acid-catalyst and thermomechanical pretreatment for improving enzymatic hydrolysis of hemp hurds. Bioresour. Technol. 2018, 257, 192-200. [CrossRef]

29. Magro, P.; Marciano, P.; Di Lenna, P. Oxalic acid production and its role in pathogenesis of Sclerotinia sclerotiorum. FEMS Microbiol. Lett. 1984, 24, 9-12. [CrossRef]

30. Arantes, V.; Qian, Y.; Milagres, A.M.F.; Jellison, J.; Goodell, B. Effect of $\mathrm{pH}$ and oxalic acid on the reduction of Fe3+ by a biomimetic chelator and on $\mathrm{Fe}^{3+}$ desorption/adsorption onto wood: Implications for brown-rot decay. Int. Biodeterior. Biodegrad. 2009, 63, 478-483. [CrossRef]

31. Beckers, S.J.; Dallo, I.A.; Del Campo, I.; Rosenauer, C.; Klein, K.; Wurm, F.R. From Compost to Colloids-Valorization of Spent Mushroom Substrate. ACS Sustain. Chem. Eng. 2019, 7, 6991-6998. [CrossRef]

32. Mohamed, M.A.; Jaafar, J.; Ismail, A.F.; Othman, M.H.D.; Rahman, M.A. Chapter 1-Fourier Transform Infrared (FTIR) Spectroscopy. In Membrane Characterization; Hilal, N., Ismail, A.F., Matsuura, T., Oatley-Radcliffe, D., Eds.; Elsevier: Amsterdam, The Netherlands, 2017; pp. 3-29. [CrossRef]

33. Lin, Y.-S.; Liang, S.-H.; Lai, W.-L.; Lee, J.-X.; Wang, Y.-P.; Liu, Y.-T.; Wang, S.-H.; Lee, M.-H. Sustainable Extraction of Chitin from Spent Pupal Shell of Black Soldier Fly. Processes 2021, 9, 976. [CrossRef]

34. Yan, T.; Wang, P.; Wang, L. Utilization of oxalic acid-modified spent mushroom substrate for removal of methylene blue from aqueous solution. Desalin. Water Treat. 2015, 55, 1007-1017. [CrossRef]

35. Singh, B.; Kumar, P.; Yadav, A.; Datta, S. Degradation of fermentation inhibitors from lignocellulosic hydrolysate liquor using immobilized bacterium, Bordetella sp. BTIITR. Chem. Eng. J. 2019, 361, 1152-1160. [CrossRef]

36. Bari, E.; Mohebby, B.; Naji, H.R.; Oladi, R.; Yilgor, N.; Nazarnezhad, N.; Ohno, K.M.; Nicholas, D.D. Monitoring the cell wall characteristics of degraded beech wood by white-rot fungi: Anatomical, chemical, and photochemical study. Maderas Cienc. Tecnol. 2018, 20, 35-56. [CrossRef]

37. Zhou, J.; Liu, G.; Wang, S.; Zhang, H.; Xu, F. TG-FTIR and Py-GC/MS study of the pyrolysis mechanism and composition of volatiles from flash pyrolysis of PVC. J. Energy Inst. 2020, 93, 2362-2370. [CrossRef] 